Document downloaded from:

http://hdl.handle.net/10251/176510

This paper must be cited as:

Minin, IV.; Minin, OV.; Delgado-Notario, JA.; Calvo-Gallego, J.; Velázquez-Pérez, JE.; Ferrando Bataller, M.; Meziani, YM. (2020). Improvement of a Terahertz Detector Performance Using the Terajet Effect in a Mesoscale Dielectric Cube: Proof of Concept. physica status solidi (RRL) - Rapid Research Letters. 14(5):1-5.

https://doi.org/10.1002/pssr.201900700

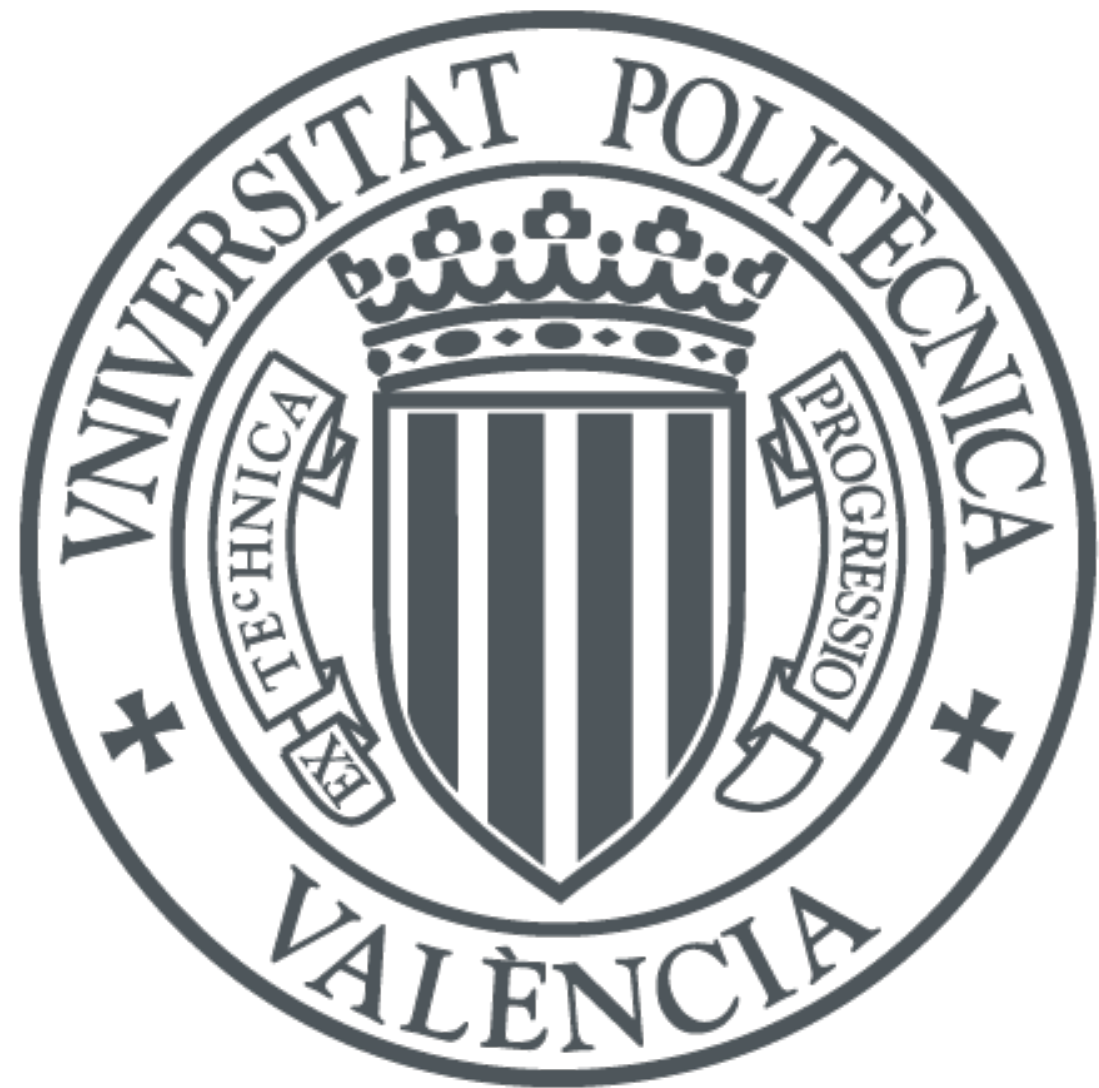

The final publication is available at

https://doi.org/10.1002/pssr.201900700

Copyright John Wiley \& Sons

Additional Information 


\section{Improvement of plasma waves terahertz detector using terajet effect in mesoscale dielectric cube: proof of concept}

\author{
Igor V Minin ${ }^{1,2}$, Oleg V Minin ${ }^{1,2}$, Yahya M. Meziani ${ }^{3,}{ }^{*}, \ldots$ \\ Tomsk Polytechnical University, Tomsk, Russia \\ Tomsk State University, Tomsk, Russia \\ ${ }^{4}$ address ...
}

Departamento de F'ısica Aplicada, Salamanca University, Salamanca, Spain

Key words: terajet, detector, sensitivity, gain

Corresponding author: e-mail meziani@usal.es

Terahertz $(\mathrm{THz})$ wave band has much attention for communication, medical, product quality control, nondestructive testing and homeland security applications, to name a few [1-4] in which detectors are one of the oldest radiation sensing techniques [5] and are a key elements [6] and so the development of sensitive detectors has attracted much interest. THz band is usually characterized by optical matching methods for the radiation flux with the receiving element by a quasioptical lens or a horn antenna [7-12]

These methods were important advancements, but they also had drawbacks since the sizes of such classical quasioptical elements usually are much larger than the wavelength and these devices could not been directly integrated with $\mathrm{THz}$ detectors, which stimulating the development of a new THz component base. Moreover, the main feature of such methods is significant diffraction limitations when radiation is introduced into the receiving elements, as a result of which limitations in sensitivity to received radiation signals appear. For example, the noise equivalent power $(N E P)$ of the receiving element depends on its volume and temperature as $[13,14]$

$$
N E P \propto T^{3} \sqrt{V}
$$

where $V$ is the volume of the receiving element and $T$ is the working temperature. From this simple equation Eq. 1 it is followed, that the minimum NEP can be reached using a decrease in volume. Accordingly, this volume should be consistent with the volume of the focusing area of the incident light. However, the diffraction effects does not allow the concentration of the radiation flow below the diffraction limit [15] without the absence of additional optical or waveguide elements. However, the presence of such additional elements usually leads to an increase in losses and an increase in the NEP value.

Due to photonics play a key role in future $\mathrm{THz}$ systems, recently, a new approaches for the resolution enhancement relying on the effects of $\mathrm{THz}$ field localization near the shadow surface of a mesoscale dielectric particles were investigated. For example, a cubic particles are a natural Mie scatterer and solid immersion lens, which can generate so called photonic terajets beyond Abbe's diffraction limit and confine the scattering within a small divergence solid angle [16-20].

The phenomena of terajet yield simple approach to boost the performance of almost any focusing system by simply placing the mesoscale dielectric particle in front of the focal area [21,22].

In this work, to increase the coupling efficiency to a radiation source with $\mathrm{THz}$ plasma waves based detector 
we use a terajet formed by teflon cube with dimensions

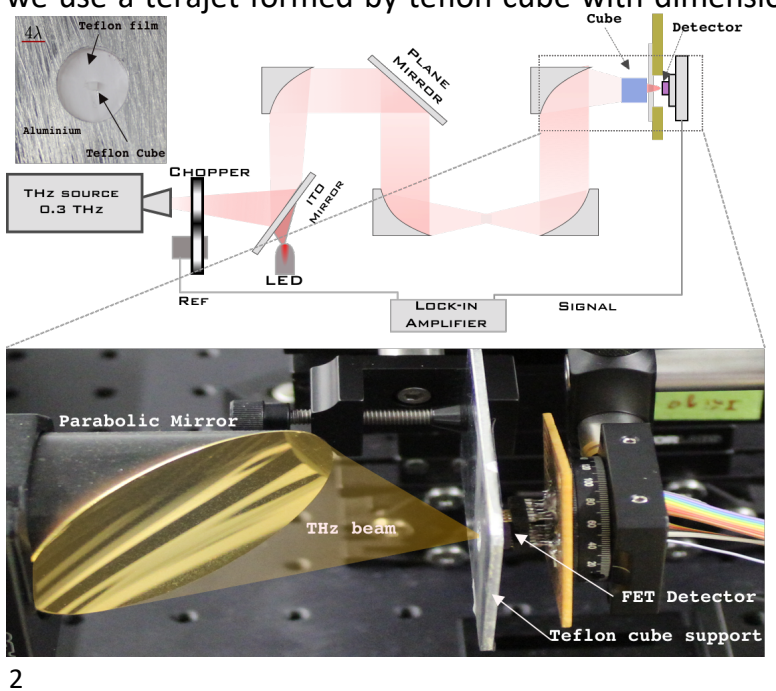

Figure 1 Schematic diagram (a) and experimental setup (b) for terahertz detector characterization.

of wavelength. A gain enhancement of around $5 \mathrm{~dB}$ was experimentally observed with slight decrease of the noise equivalent power value.

A plasma waves based field effect transistor was used for the detection of the terahertz radiation. It's a strained silicon Modulation field effect transistor based on Si/SiGe system. More information of the device could be found in ref. [24]. A Dielectric Resonant Oscillator (DRO) at $12 \mathrm{GHz}$ with series of frequency multipliers were used to emit at frequency of $0.3 \mathrm{THz}$. The output power, $6 \mathrm{~mW}$, was measured close to the output of the source using a calibrated pyroelectric detector. The $\mathrm{THz}$ beam was collimated and focused by off-axis gold coated parabolic mirrors as shown in figure 1 . The photo-induced drain-tosource voltage $\Delta U$ was measured using a lock-in technique where the $\mathrm{THz}$ beam was chopped at $298 \mathrm{~Hz}$. A visible laser in combination with an indium tin oxide (ITO) mirror was used for the alignment of the $\mathrm{THz}$ beam

1. More detailed information according experimental setup may be fined in [23].

A 1x1x1 mm3 Teflon cube was fixed on a $100 \mu \mathrm{m}$ film with glue transparent in $\mathrm{THz}$ of the Teflon and placed on an XYZ stage in the front of the detector (Fig.1). An aluminium plate with a hole of around $100 \mathrm{~mm}$ was used to hold the cube and the Teflon film (see insert in Fig.1). The beam spot diameter was about $2 \mathrm{~mm}$ at the frequency of $300 \mathrm{GHz}$ was centered with a cube and the area of the detector, including the contact pads, was less than $0.05 \mathrm{~mm}^{2}$ [24].

The effect of terajet formation near the shadow surface of dielectric cube is shown in figure 2. Numerical model of the cubic particle was built in the commercial FEM software package-CST Microwave Studio. A mesh size was selected as $* * * * * 8$. A plane wave of $1-\mathrm{mm}$ wavelength equalling to $300 \mathrm{GHz}$ frequency propagates from $+z$ to $-z$ direction with a polarisation along $y$ axis which is vertical to the optical bench in the experiment. Optical properties - refractive index, $n$, and extinction coefficient, $k$, for Teflon ( $n=1.43, k=0.00014$ ) are based on the previous results [19].

It is clearly seen that near the rear surface of the cubic particle there is a localization (focusing) of the radiation incident on it with a maximum value of electric field enhancement about of $E^{2} \sim 9 \mathrm{~V}^{2} / \mathrm{m}^{2}$. The Full Width at Half Maximum (FWHM) [25] about $0.4 \lambda$ along $X$-axis and FWHM about $0.5 \lambda$ along Y-axis with the length of a terajet (defined as a Full Length at Half Maximum) about one of wavelength are observed.

So at measurement of detector characteristics the distance between shadow surface of a cube and detector was about the length of terajet.

The photoresponse was performed without the cube. Then, the cube was placed in the focal plane of the $\mathrm{THz}$ beam and the measurement repeated. The Responsivity $(<)$ was extracted from the measured data via:

$$
\Re_{i}=\frac{\pi}{\sqrt{2}} \frac{\Delta U}{P} \frac{S_{t}}{S_{a}}
$$

where $P$ is the $\mathrm{THz}$ power incident on the transistor ( 1 $\mathrm{mW}$ at the device position), measured by a calibrated pyroelectric detector. The factor $\pi / \sqrt{2}$ comes from the Fourier transform of the square-wave modulated $\mathrm{THz}$ signal detected as its rms value by the lock-in amplifier. $S_{t}$ denotes the $\mathrm{THz}$ beam area given by $S_{t}=\pi r^{2}$ where $r=1.5$ $\mathrm{mm}$ is the radius of the beam spot at $0.3 \mathrm{THz}$. $S_{a}$ is the active area of the detector which it was replaced by the diffraction limit area $S_{\lambda}=\lambda^{2} / 4$ in equation 2. A maximum responsivity close to $22 \mathrm{~V} / \mathrm{W}$ was obtained with a gate voltage $\left(\mathrm{V}_{\mathrm{g}}\right)$ close to the threshold voltage $\left(\mathrm{V}_{\mathrm{th}} \sim-0.8 \mathrm{~V}\right)$ when no cube was used (Fig. 3). The responsivity was increased up to $36 \mathrm{~V} / \mathrm{W}$ with introduction of the cube. This gives a gain of around $5 \mathrm{~dB}$. The NEP was also deduced from responsivity[23] by using the following formula:

$$
N E P=\frac{N}{\Re}
$$


where $N$ is the noise spectral density of the transistor in

$\mathrm{V} / \sqrt{\mathrm{Hz}}$. Since no $\mathrm{V}_{\mathrm{DS}}$ bias was applied to the channel, we assumed that thermal noise $\left(N_{t h}\right)$ is the only source of noise in measurements. Hence, $N=N_{t h}=\sqrt{4} k_{B} T \overline{R_{S D}}$ where $T$ is temperature. The channel resistance RsD was extracted from the transfer characteristics of the transistor at $V_{D S}=100 \sqrt{\mathrm{mV}}$. A minimum value of NEP was $\mathrm{f} \sqrt{\text { ound }}$ to be $200 \mathrm{pW} / \mathrm{Hz}$ without the cube and $120 \mathrm{pW} /$ $\mathrm{Hz}$ with the cube (Fig. 3) at a gate voltage close to the threshold voltage and equal to $-0.8 \mathrm{~V}$.

Conclusion From Radar range maximum detection formula determinate how Rmax increase if we increase the gain to $4 \mathrm{~dB}$

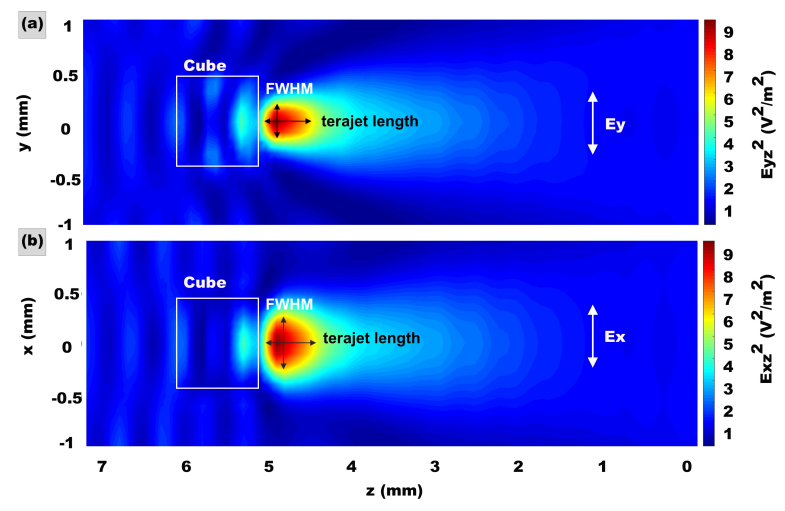

pss header will be provided by the publisher
Figure 3 (left) Responsivity versus gate voltage with and without the use of the teflon cube. (right) The obtained NEP for both cases.

It is shown that use of terajet effect in wavelength scaled dielectric cuboid particle-lens opens a new degree of freedom in designing efficient field localizations for sensitivity enhancement of $\mathrm{THz}$ detectors with minor decreasing (about 1.67 times) of NEP value.

Acknowledgements This work was partially supported by the Russian Foundation for Basic Research (Grant No. 20-57S52001)

\section{References}

[1] S. S. Dhillon, et al. J. of Physics D: Applied Physics, 50(4), 043001 (2017)

[2] N. Chernomyrdin, A. Kucheryavenko, G. Kolontaeva, G. Katyba, P. Karalkin,V. Parfenov, A. Gryadunova, A. Norkin, O. Smolyanskaya, O.V. Minin, I.V. Minin, V. Karasik and K. Zaytsev. Proc. SPIE 10677, Unconventional Optical Imaging, 106771Y (2018); DOI 10.1117/12.2306132

[3] I.V. Minin and O.V. Minin. Proc. SPIE 4129, Subsurface Sensing Technologies and Applications II, (6 July 2000); doi: 10.1117/12.390666

[4] Y. Samura, K. Horio, V. Antipov, S. Shipilov, A. Eremeev, O. V. Minin, I. V. Minin and S. Hisatake. IEEE Antennas and
Figure 2 Simulation results of terajet formation for electric (a) and magnetic (b) components of field intensity

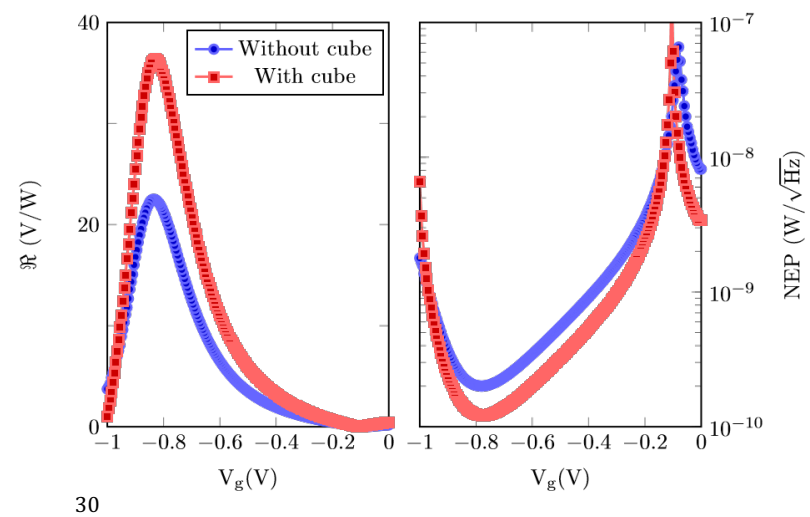

10
Wireless Propagation Letters, 18(9), 1828-1832 (2019); DOI 10.1109/LAWP.2019.2930820

[5] S.P. Langley. Proceedings of the American Academy of Arts and Sciences, 16(342), JSTOR (1880).

[6] F. Sizov. Semicond. Sci. Technol. 33, 123001 (2018); DOI 10.1088/1361-6641/aae473

[7] X. Gao, T. Zhang, J. Du, A.R. Weily, Y. J. Guo and C. P. Foley. Supercond. Sci. Technol. 30095011 (2017)

[8] X. Tu, L. Kang, C. Wan, L. Xu, Q. Mao, P. Xiao, X. Jia, W. Dou, J. Chen, and P. Wu. Opt. Express, 23(11), 13794 (2015)

[9] I. V. Minin, O. V. Minin, Y. Triandaphilov and V. Kotlyar. Progress in Electromagnetics Research B, 7, 257-264 (2008); DOI 10.2528/PIERB08041501

[10] D. Armand, H. Taniguchi, Y. Kadoya, T. Tanaka, and K. Tanaka. Appl. Phys. Lett. 102(14), 141115 (2013).

[11] T. Harter, S. Ummethala, M. Blaicher, S. Muehlbrandt, S. Wolf, M. Weber, M. Adib, J. Kemal, M. Merboldt,F. Boes, S. Nellen, A. Tessmann, M. Walther, B. Globisch, T. Zwick, W. Freude, S. Randel, and C. Koos. Optica, 6(8),1063-1070 (2019); DOI 10.1364/OPTICA.6.001063

[12] A. Kazemi, Q. Shu, V. Dahiya, Z. Taghipour, P. Paradis, C. Ball, T. Ronningen, S. Zollner, S. Young, J. Budhu, K. Grossklaus, T. Vandervelde, A. Grbic, and S. Krishna. Proc. SPIE 11002, Infrared Technology and Applications XLV, 1100221 (7 May 2019); DOI 10.1117/12.2518807

[13] B. Karasik, W. McGrath, H. LeDuc, and M. Gershenson. Supercond. Sci. Technol. 12, 745 (1999).

[14] G. Hyseni, N. Caka, K. Hyseni. WSEAS Transactions on 
Circuits and Systems 9(4), 238-247 (2010)

[15] E. Abbe. Arch. Mikrosk. Anat., 9, 413-468 (1873)

[16] V. Pacheco-Pena, M. Beruete, I. V. Minin, and O. V. Minin. Appl. Phys. Lett., 105(8), 084102 (2014).

[17] V. Pacheco-Pena, M. Beruete, I. V. Minin, and O.V. Minin. Opt. Lett., 40(2), 245-248 (2015).

[18] O.V. Minin, I.V. Minin. Optical and Quantum Electronics, 49, 326 (2017).

[19] L. Yue, B. Yan, J. Monks, Z. Wang, N. Tung, V. Lam, O.V. Minin, and I.V. Minin. J. of Infrared, Millimeter, and Terahertz Waves, 39(6), 546-552 (2018).

[20] H. Pham, S. Hisatake, I.V. Minin, O.V. Minin, and T. Nagatsuma. Appl. Phys. Lett., 108(19) 2016
[21] I.V. Minin, O.V. Minin, V. Pacheco-Pena, M. Beruete. Appl. Phys. Lett., 106, 254102 (2015)

[22] H. Nguyen Pham, S. Hisatake, O.V. Minin, T. Nagatsuma and I.V. Minin. APL Photonics 2, 056106 (2017); DOI 10.1063/1.4983114

[23] E. Javadi, J.A. Delgado-Notario, N. Masoumi, M. Shahabadi, J.E. Velazquez-Perez, and Y.M. Meziani. Phys. Sta-' tus Solidi A, 1700607 (2018), DOI 10.1002/pssa.201700607 [24] Delgado-Notario, J. A., Velazquez-Perez, J. E., Meziani, Y. M., and Fobelets, K. (2018). Sub-THz imaging using nonresonant HEMT detectors. Sensors (Switzerland), 18(2). https://doi.org/10.3390/s18020543 [25] W.V.

Houston. Phys. Rev. 29, 0478-0484 (1927). 